\title{
USE PROPERTIES OF DISTRIBUTIONS TO MODEL THE SYSTEMS WITH SEVERE NONLINEARITIES

\author{
Emil Pop $^{1}$, Gabriel Ilcea ${ }^{2}$, Sergiu Buzdugan ${ }^{3}$
}

\begin{abstract}
Many times, in science and technology, we need to model and simulate some phenomena and with this we encounter lots of difficulties caused by the presence of certain nonlinear elements, which cannot be linearly approximated, called severe nonlinearities. This kind of nonlinearities contains discontinuities and non-derivable points. In other words, many nonlinearities are defined by some relations and not by the functions. This situation appears most frequently in the study of the systems when we have a mathematical model to simulate them. A solution proposed in this paper is to use a distributions theory that extends the class of functions. In order to refer to the class of nonlinear systems for which the theory of distributions will be applied, a brief presentation of nonlinear systems versus linear systems will be made. In the following paper the distribution concept, the elementary distributions were defined and several distributions and properties were illustrated by a simulation. Using properties of distributions, complex nonlinear problems, like control systems design, can be treated much easy. In this paper we can see models and simulations results for several discrete control applications used in control engineering and power electronics. The distributions are suitable for software implementation and by this offers very good support for embedded systems with software-oriented solution. Many distributions models were known for a long time, but were not used in applications. In this paper the distributions are modeled, simulated and many applications which can be used as guides in the future, was developed. As a conclusion, the distribution properties are very suitable for the development of nonlinear mathematical models especially for ones with severe nonlinearities, and through this to design controllers or other nonlinear devices.
\end{abstract}

UDC Classification: 519.6; DOI: http://dx.doi.org/10.12955/cbup.v6.1308

Keywords: Nonlinear Systems, Distributions Properties, Simulink Models, Simulations, Applications

\section{Introduction}

The linear systems are described by the linear general equations in vector spaces. Suppose that variable $\mathrm{u} \in \mathrm{R}^{\mathrm{p}}, \mathrm{x} \in \mathrm{R}^{\mathrm{n}}$, y $\in \mathrm{R}^{\mathrm{q}}$ are input, state and output vectors and $\mathrm{A}, \mathrm{B}, \mathrm{C}, \mathrm{D}$ are real values matrices with appropriate dimensions then the linear systems equations (Kalman et al., 1969):

$$
\begin{aligned}
& \frac{d x}{d t}=A \cdot x+B \cdot u \\
& y=C \cdot x+D \cdot u
\end{aligned}
$$

These very simple equations (use only addition and multiplication by constant operations) are very comfortable to be used in science and technology and has a good theory and applications. Unfortunately, in the real world, process and phenomena are nonlinear, so real systems are nonlinear to. Linear equations of systems represent an approximation of real systems, but in many circumstances are unacceptable. In these cases, a better strategy is to model and simulate the systems by its nonlinear mathematical models. This is a good point but for a large class of nonlinear systems, nonlinearities are discontinued, have points which are non-derivative, or are defined by relationships which are difficult to approach. Nonlinear systems are defined as systems which use nonlinear operators to describe their mathematical models. This approach is exhaustive, including in the same class of the systems a wide variety of mathematical equations and it is impossible to find the general equations for entire nonlinear system classes. Unfortunately, there isn't yet a nonlinear systems theory. There are only several methods to analyze some classes of nonlinear systems (Bolton, 1998).

If the input, state and output are vectors: $u \in R^{p}, x \in R^{n}, y \in R^{q}$ and nonlinear vector functions $F, G \in C^{1}$, a mathematical model for continuous nonlinear dynamical systems is (Bertolonffy, 1972):

$$
\begin{aligned}
& \frac{d x}{d t}=F(x, u) \\
& y=G(x . u)
\end{aligned}
$$

A class of nonlinear systems, named "Separable nonlinear systems", have feedback between a linear process and nonlinear controller. The operator $\mathrm{F}$ is nonlinear depending on the error $\varepsilon$ defining the controller and $G$ defining the linear function with the transfer function $G(s)$ independent of $u$. The equations are:

\footnotetext{
${ }^{1}$ University of Petrosani, Romania, emilpop@upet.ro

${ }^{2}$ University of Petrosani, Romania, gabi_ilcea@yahoo.com

${ }^{3}$ Technical University of Cluj-Napoca, Romania, sergiu_buzdugan@yahoo.com
} 


$$
\begin{aligned}
& x=F(\varepsilon) ; \varepsilon=u-y \\
& y=G(s) \cdot x(s)
\end{aligned}
$$

In fig. 1a is presented the diagram of a Separable nonlinear system (Ionescu \& Varga , 1994).

Figure 1: Separable nonlinear system with severe nonlinearities

The nonlinearities can be classified as light and severe, according to the possibility of their linearization. The light nonlinearities have a good linear approximation, while for severe nonlinearities the linear approximation has unacceptable errors. Based on nonlinearities from the systems we can classify them into two big classes: Light nonlinear systems and Severe nonlinear systems. Many systems with severe nonlinearities have singularities like: discontinuities, non-derivable points, polymorph outputs or there are no functions etc. In fig. $1 \mathrm{~b}, \mathrm{c}$ is shown two examples of severe nonlinearities. A polymorph with hysteresis (b) and a non-derivable with discontinuities points (c).

Generally speaking, light nonlinearities are continuous and differentiable, while the severe ones are not differentiable and are discontinuous. The second category includes a wide range of switching elements used in control engineering like digital elements, relays, PLC etc.

Many times, for Severe nonlinear systems it is difficult to write a mathematical model, because of these nonlinearities. This is a difficult barrier. In the classical theory this region is avoided. This approach has two disadvantages: first, the representation is complicated and unusual, and second, the discontinuities are eliminated just where the systems work. These difficulties can be eliminated with distribution theory which extend the fundamental concepts, like derivability, to the whole domain, and can be relatively easy to evaluate the functions qualitative properties, like: convergence and stability. On the other hand, this approach permits to create a closed relation for the systems and from here will be assure an easy modeling and simulation procedure. For example, for the nonlinearity of Fig.2.c, a closed formula cannot be written, but just be divided by intervals of equations (4), (Pop \& Bubatu, 2012):

$$
y=\left\{\begin{array}{c}
-B ; u<-a_{1} \\
0 ;-a_{1} \leq u<b \\
B ; u \geq b
\end{array}\right\} \frac{d u}{d t}>0 ; y=\left\{\begin{array}{c}
B ; u<a_{1} \\
0 ;-b_{1} \leq u<a \\
-B ; u<b_{1}
\end{array}\right\} \frac{d u}{d t}<0
$$

The equations above are unacceptable for modeling and simulation. For this reason, in this paper we present alternative solutions using distributions and their properties which permit easier modeling and simulating severe nonlinear systems.

\section{Distributions concept, elementary distributions and its properties}

Distributions are functional transformations between linear spaces (Schwartz L., 1951).

Consider the $\mathrm{n}$-dimensional Euclidian real space $\mathrm{R}^{\mathrm{n}}$, organized as vectors of space. The elements of this space are n-coordinates vectors: $x=\left(x_{1}, x_{2}, \ldots, x_{n}\right)$.

On this space will be considered the applications of forms $f: R^{n} \rightarrow R$ (Zemanian, 1998).

From these applications will be selected applications $\varphi(x)$ which are continuous, derivable and the derivates are continuous with zero value out of their domain. The domain of these functions is compact.

The space of $\varphi(x)$ functions continuous and derivable is $\mathrm{K}^{\mathrm{n}}$ and has the properties (Davies, 1998):

$$
\begin{gathered}
\forall \varphi_{1}(\mathrm{x}), \varphi_{2}(\mathrm{x}) \in \mathrm{K}^{\mathrm{m}}, \alpha, \beta \in \mathrm{R}^{\mathrm{n}}: \alpha \cdot \varphi_{1}(\mathrm{x})+\beta \cdot \varphi_{2}(\mathrm{x}) \in \mathrm{K}^{\mathrm{n}} \\
\forall \varphi_{\mathrm{k}}(\mathrm{x}) \in \mathrm{K}^{\mathrm{m}}: \lim _{\mathrm{k} \rightarrow \infty}\left|\varphi_{\mathrm{k}}(\mathrm{x})\right|=0 .
\end{gathered}
$$


This is a fundamental space. In this space will be defined the functional applications:

$$
f: K^{m} \rightarrow R: \quad f[\varphi(x)] \in R .
$$

Distributions are real, linear and continuous functional defined fundamental space. The most used distributions are: pulse, step and ramp (Teodorescu et al., 2013).

1. The pulse distribution or Dirac pulse $\delta(\mathrm{x})$ is defined as follows.):

$$
\begin{aligned}
\delta: K^{m} \rightarrow R: \quad & \delta[\varphi(x)]=\varphi(0) ; \forall \varphi(x) \in K^{m} \\
\delta(x)= & \left\{\begin{array}{ll}
0 ; & x \neq 0 \\
\infty ; & x=0
\end{array} ; \int_{R} \delta(x) d x=1\right.
\end{aligned}
$$

Figure 2: Distribution $\delta(\mathrm{x})$ and its properties

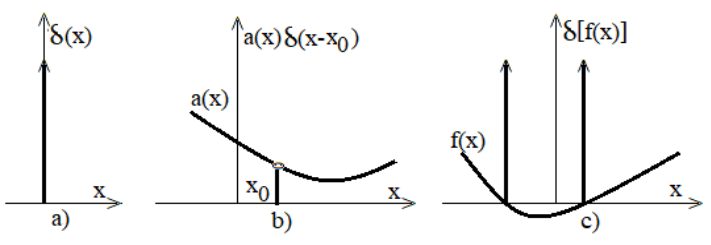

Source: Ilcea (2017)

Some important properties of Dirac distribution are presented billow:

$$
\begin{aligned}
& a(x) \cdot \delta\left(x-x_{0}\right)=a\left(x_{0}\right) \cdot \delta\left(x-x_{0}\right) ; \text { (fig.2.b) } \\
& \delta[f(x)]=\sum_{i=1}^{p} \frac{1}{\left|f^{\prime}\left(x_{i}\right)\right|} \cdot \delta\left(x-x_{i}\right) \\
& \frac{d[f(x)]}{d x}=f(x)^{\prime}+\sum_{i=1}^{p} s_{i} \cdot \delta\left(x-x_{i}\right) \quad ; s_{i}=f\left(x_{i}+0\right)-f\left(x_{i}-0\right), \text { (fig.2.d) }
\end{aligned}
$$

2. The step or Heaviside distribution $\theta(\mathrm{x})$ is defined bellow (Gerard \& Sursh John, 1998):

$$
\theta: K^{m} \rightarrow R ; \quad \theta[\varphi(x)]= \begin{cases}1 ; & x \geq 0 \\ 0 ; & x<0\end{cases}
$$

Figure 3: Heaviside distribution and properties

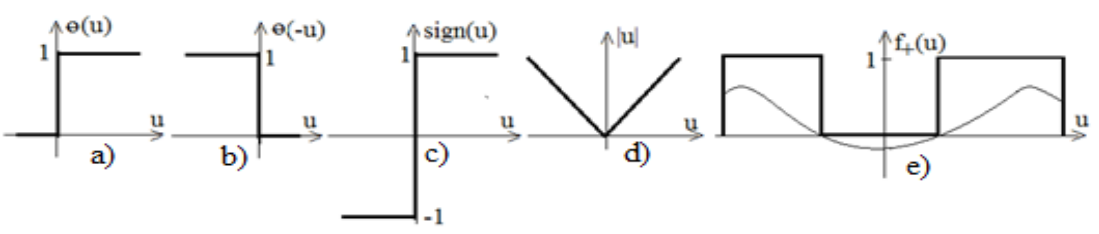

Source: Pop (2018)

Some important properties of $\theta(\mathrm{x})$ are presented below and in Fig.3 are shown the graphic form of the below equations.

$$
\begin{gathered}
\theta(-x)=1-\theta(x)_{(\text {fig.3.b) }} \\
\theta(x)-\theta(-x)=\operatorname{sign}(x)_{(\text {fig.3.c) }} \\
x \cdot \operatorname{sign}(x)=|x|_{(\text {fig.3.d) }} \\
\mathrm{f(x)} \theta[f(x)]=f_{+}(x) \quad \text { (fig.3.e) }
\end{gathered}
$$




$$
\frac{d[\theta(x)]}{d x}=\delta(x)
$$

3. The ramp distribution is defined as follows (Ian Richards \& Youn Heekyung, 2013):

$$
r: K^{m} \rightarrow R ; \quad r[\varphi(x)]= \begin{cases}x ; & x \geq 0 \\ 0 ; & x<0\end{cases}
$$

The ramp distribution and its properties are presented below (Kecs, 2003).

\begin{tabular}{c}
\hline Figure 4: Ramp distribution and properties \\
\hline Source: Popa (2018) \\
$\qquad(x)=x \cdot \theta(x)=x_{+}($ramp) (fig.4.a); \\
$-x \cdot \theta(-x)=x_{-}($negative ramp) (fig.4.b); \\
$r\left(x^{2}-a^{2}\right)=\theta(x-a) \cdot(x-a)+\theta(x+a) \cdot(x+a)($ fig.4.c); \\
$\frac{d[r(x)]}{d x}=\theta(x)$
\end{tabular}

The elementary distributions are connected to each other by the following relationships:

$$
\delta(u)=\frac{d \theta(u)}{d u}=\frac{d^{2} r(u)}{d u^{2}} ; \quad 1(u)=\theta(u)+\theta(-u)
$$

In fig. 5 are shown the diagrams of these distributions.

\begin{tabular}{|l|l|l|c|}
\hline Figure 5: Elementary distributions relationship \\
\hline Source: $\operatorname{Pop}(2018)$ & b) \\
\hline
\end{tabular}

4. Other distributions

Combining elementary distributions, we obtained other important distributions as follows:

$$
\begin{aligned}
& \lambda(\mathrm{u}):[\mathrm{a}, \mathrm{b}]->\{0,1\} ; \lambda=1, \mathrm{u} \in[\mathrm{a}, \mathrm{b}], \lambda_{0}=0 ; \mathrm{u} \notin[\mathrm{a}, \mathrm{b}] ; \lambda(\mathrm{u})=\theta(\mathrm{u}-\mathrm{a})-\theta(\mathrm{u}-\mathrm{b}) \\
& \lambda_{+}(\mathrm{u}):[\mathrm{a}, \mathrm{b}]->\{0,1\} ; \lambda_{+}=1, \mathrm{du} / \mathrm{dt}>0, \lambda_{+}=0 ; \mathrm{d} / \mathrm{dt}<0 ; \lambda_{+}(\mathrm{u})=\theta[\mathrm{du} / \mathrm{dt}] \\
& \lambda_{-}(\mathrm{u}):[\mathrm{a}, \mathrm{b}]->\{0,1\} ; \lambda_{-}=1, \mathrm{du} / \mathrm{dt}<0, \lambda_{-}=0 ; \mathrm{du} / \mathrm{dt}>0 ; \lambda_{-}(\mathrm{u})=\theta[-\mathrm{du} / \mathrm{dt}]
\end{aligned}
$$

The first distribution shows if $\mathrm{u}$ is element on interval $[\mathrm{a}, \mathrm{b}]$, the second distribution show if $\mathrm{u}$ increase on interval $[\mathrm{a}, \mathrm{b}]$ and third distribution's shows if $\mathrm{u}$ decreases. A distribution named Concatenation property will be defined below:

Consider $\mathrm{f}_{\mathrm{i}}(\mathrm{u})$, i $\in \mathrm{N}$ a set of real functions or distributions defined on closed interval $\left[\mathrm{a}_{\mathrm{i}}, \mathrm{b}_{\mathrm{i}}\right]$ and distribution $\theta(\mathrm{x})$. The new distribution $\mathrm{f}(\mathrm{u})$ consisting by concatenation of $\mathrm{f}_{\mathrm{i}}(\mathrm{u})$ is given by the formula:

$$
f(u)=\sum_{i}\left[f_{i}(u) \cdot\left[\theta\left(u-a_{i}\right)-\theta\left(u-b_{i}\right)\right] \cdot \theta( \pm d u / d t)\right]
$$


The sign of the expression above is "+" if $u$ increase on interval $[a, b]$ or "-_ "if $u$ decreases.

5. Using distributions properties to written the input/output equations of severe nonlinear element The distributions properties emphases before will be applied to write the formula for the severe nonlinear elements (Dunning, 2006). In fig.6. are presented 4 nonlinear elements, which are specific for relays.

These are the following: relay on-off, relay on-off with hysteresis, relay two-state, relay tri-state. If we add to the last 2, hysteresis we get relay two-state with window and relay tri-state with hysteresis.

The equations below (26) are in order for: relay on-off, relay on-off with hysteresis, relay two-state, relay two-state with window, relay tri-state, relay tri-state with hysteresis.

Figure 6: Severe nonlinear relays: a) on-off; b) on-off with hysteresis; c) two-state d) tri-state

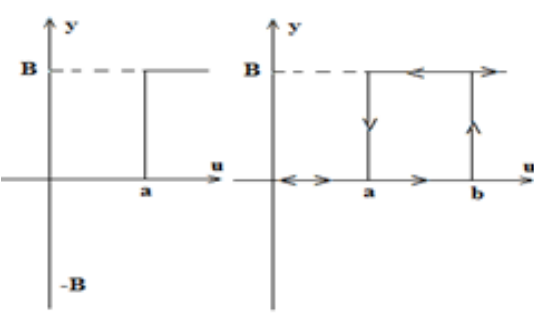

a)

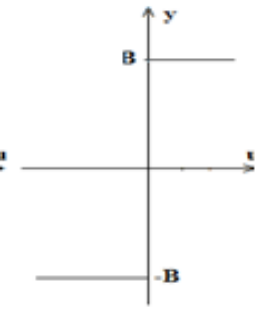

c)

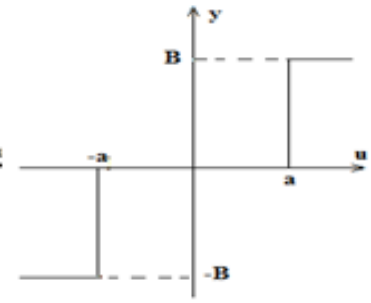

d)

Source: Popa (2017)

$$
\begin{gathered}
y(u)=B \cdot \theta(u-a) ; \\
y(u)=B \cdot[\theta(u-b) \cdot \theta(d u / d t)+\theta(u-a) \cdot \theta(-d u / d t)] \\
y(u)=B \cdot \operatorname{sign}(u) ; \\
y(u)=B \cdot[\operatorname{sign}(u-a) \cdot \theta(d u / d t)+\operatorname{sign}(u+a) \cdot \theta(-d u / d t)] ; \\
y(u)=B \cdot[\theta(u-a)-\theta(-u-a)] ; \\
y(u)=\frac{B}{2} \cdot\{[\operatorname{sign}(u-b)+\operatorname{sign}(u-a)] \cdot \theta(d u / d t)+[\operatorname{sign}(u+b)+\operatorname{sign}(u+a)] \cdot \theta(-d u / d t)\}
\end{gathered}
$$

\section{Simulation of distributions}

In this section the distributions and some properties of these will be simulated (Mohan, 2014). In Fig.7 the model of $\delta(t), \theta(t), r(t)$ were simulated using a function $\sin (2$.pi.f.t) as input.

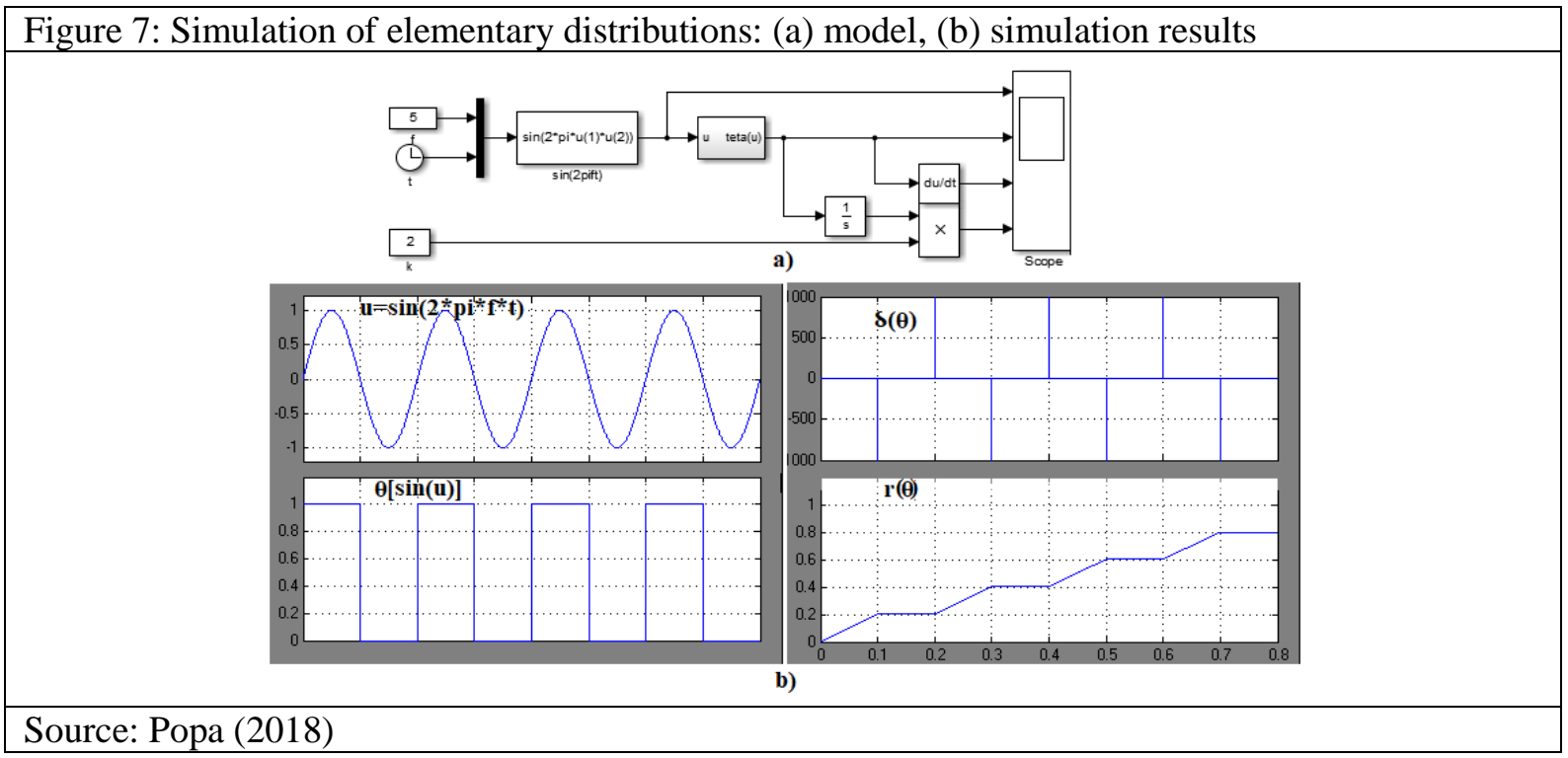

In fig. 8 the relay controller's characteristics are simulated, beginning from the relations (26). 


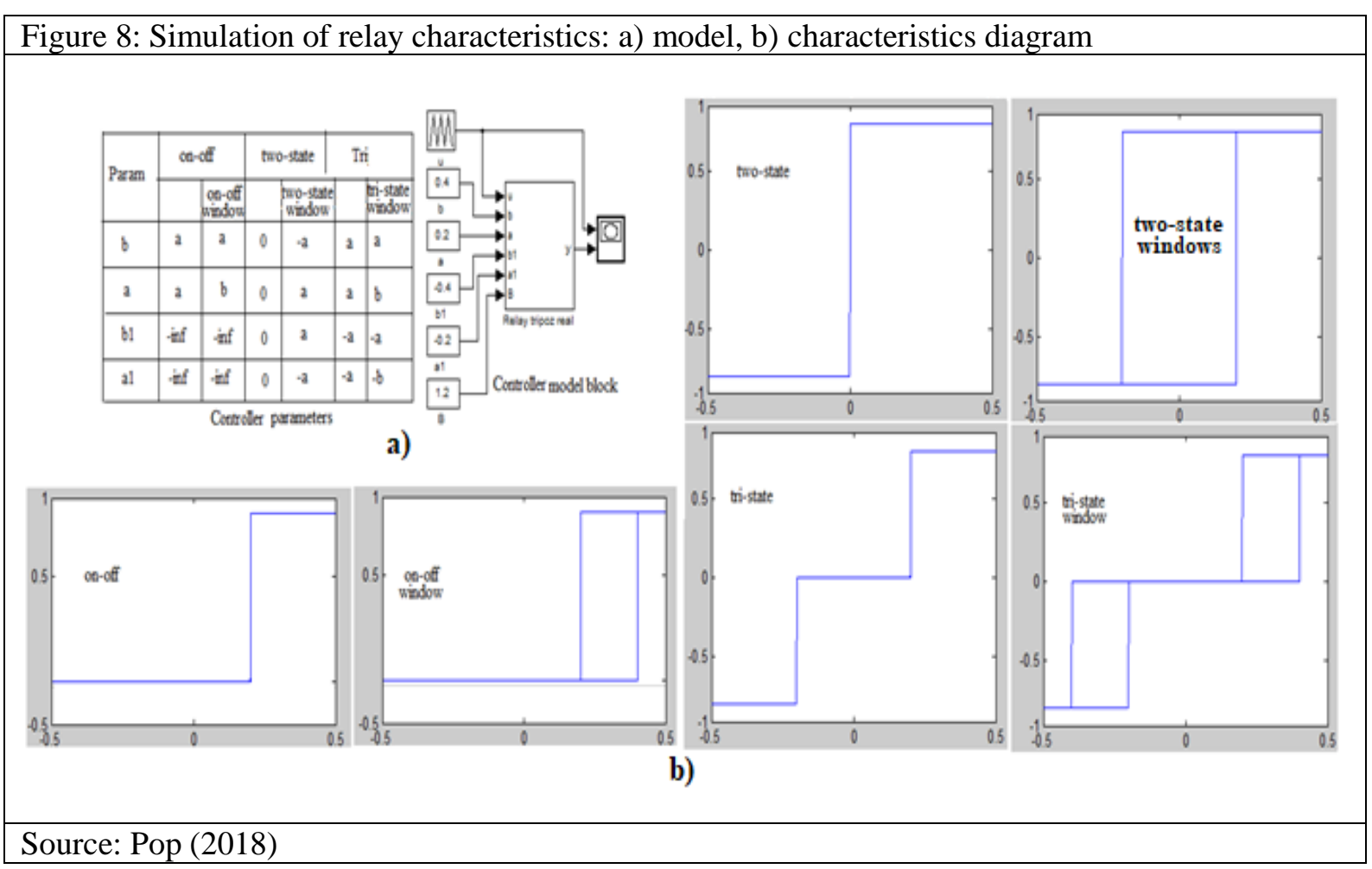

\section{Applications}

- Triangles waves

In this section we present several nonlinear system applications (Leonhard, 1996). The first application presents a generator of triangle waves with variable frequency and amplitude, TRW(f,t), as shown in Fig.9. Will be use a relation with distributions:

$$
T(p, f, t)=\int_{0}^{t} 4 \cdot p \cdot f \cdot \operatorname{sign}[\cos (2 \cdot \pi \cdot f \cdot p \cdot t)] d t
$$
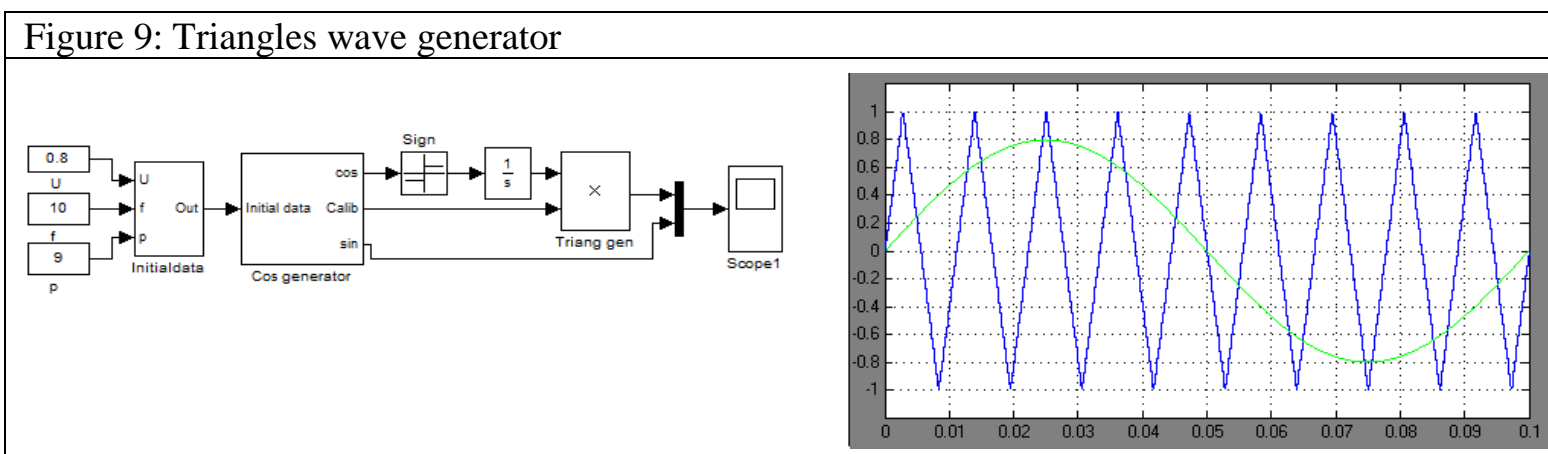

Source: Ilcea (2018)

- Separable nonlinear system

The second application is presented in fig. 10 which consist of a DC servo with encoder and a Threestate nonlinear controller with adaptive windows (Constantinescu \& Soal, 1999). Transfer functions of encoder and servo are $\mathrm{H}(\mathrm{s})=1, \mathrm{G}(\mathrm{s})=\mathrm{k} /[\mathrm{s}(1+\mathrm{Ts})]$. The data are $\mathrm{T}=2 \mathrm{~s}, \mathrm{k}=3, \mathrm{~B}=1, \mathrm{a}=0.1, \mathrm{~b}=0.12$.

Figure 10: Separable system with DC servo and Three state adaptive controller

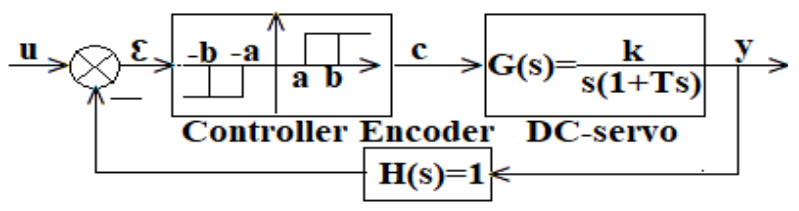

Source: Ilcea (2017) 
From the block diagram beforehand, we get the equations $y=f(x), x=f(\varepsilon), \varepsilon=u-y$. Using the distributions properties developed beforehand the state equations are presented below:

$\left.\frac{d y}{d t}=x ; \frac{d x}{d t}=-\frac{x}{T}+\frac{k B}{2 T}\{[\theta(-\varepsilon-a)-\theta(\varepsilon-b)]] y_{+}(\varepsilon)+[\theta(-\varepsilon-b)-\theta(\varepsilon-a)] y_{-}(\varepsilon)\right\}$

In fig. 11 is shown the Simulation model a), Simulation response b) and output stabilizations in the state plane c), for the DC servo control system. Notice that the controller has an adaptive loop which after 12 seconds forces the output to go in the steady state.

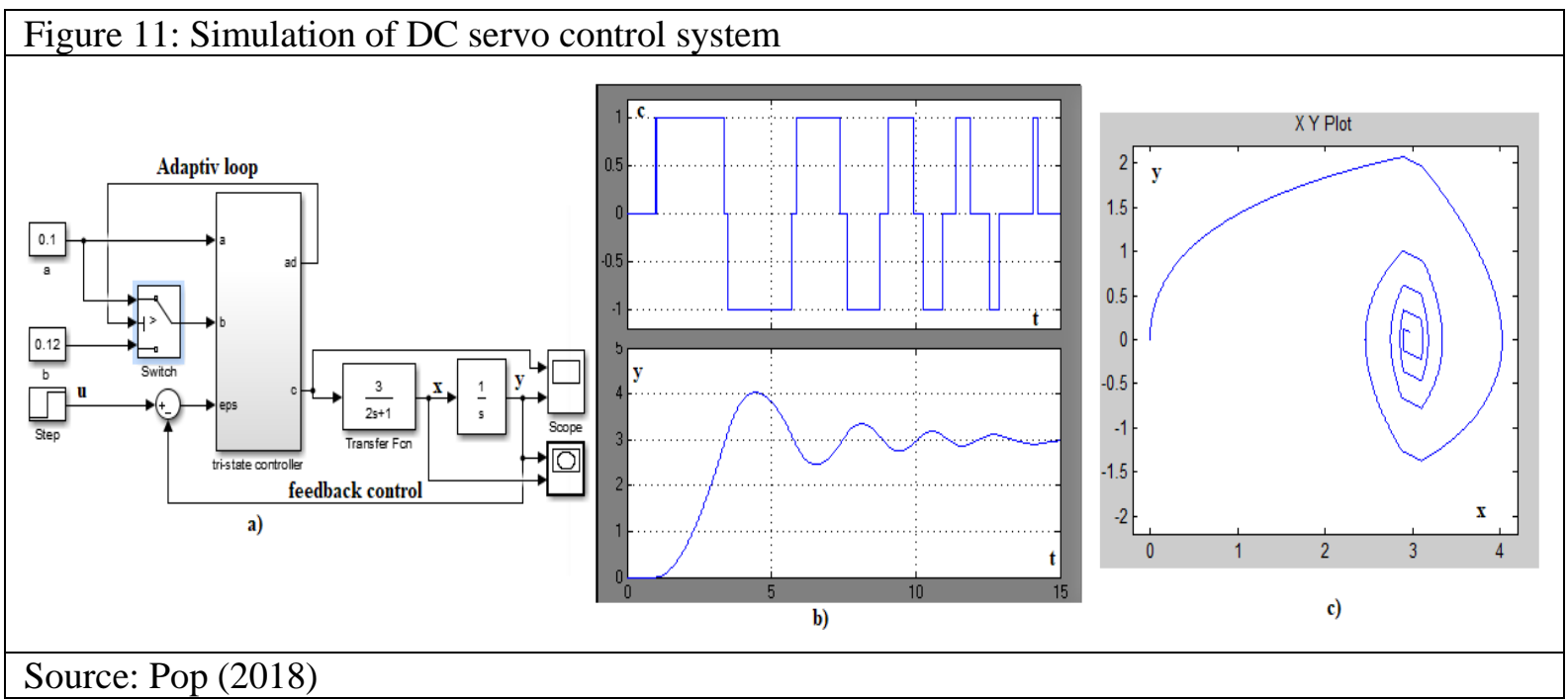

- PWM controller

The application in Fig.12 is a PWM controller. This gives an electronic inverter the pulses to produce three phase voltages with controlled frequency (Boldea \& Nasar, 1992). The model of fig.12a consist of the following blocks: Reference three phased voltages generator and triangle wave generator as shown in Fig. 12b. The triangle functions modulate the three phased functions and through comparators and $\theta$ distributions at the output we get PWM pluses as in Fig.12c (Boldea \& Nasar, 1992).

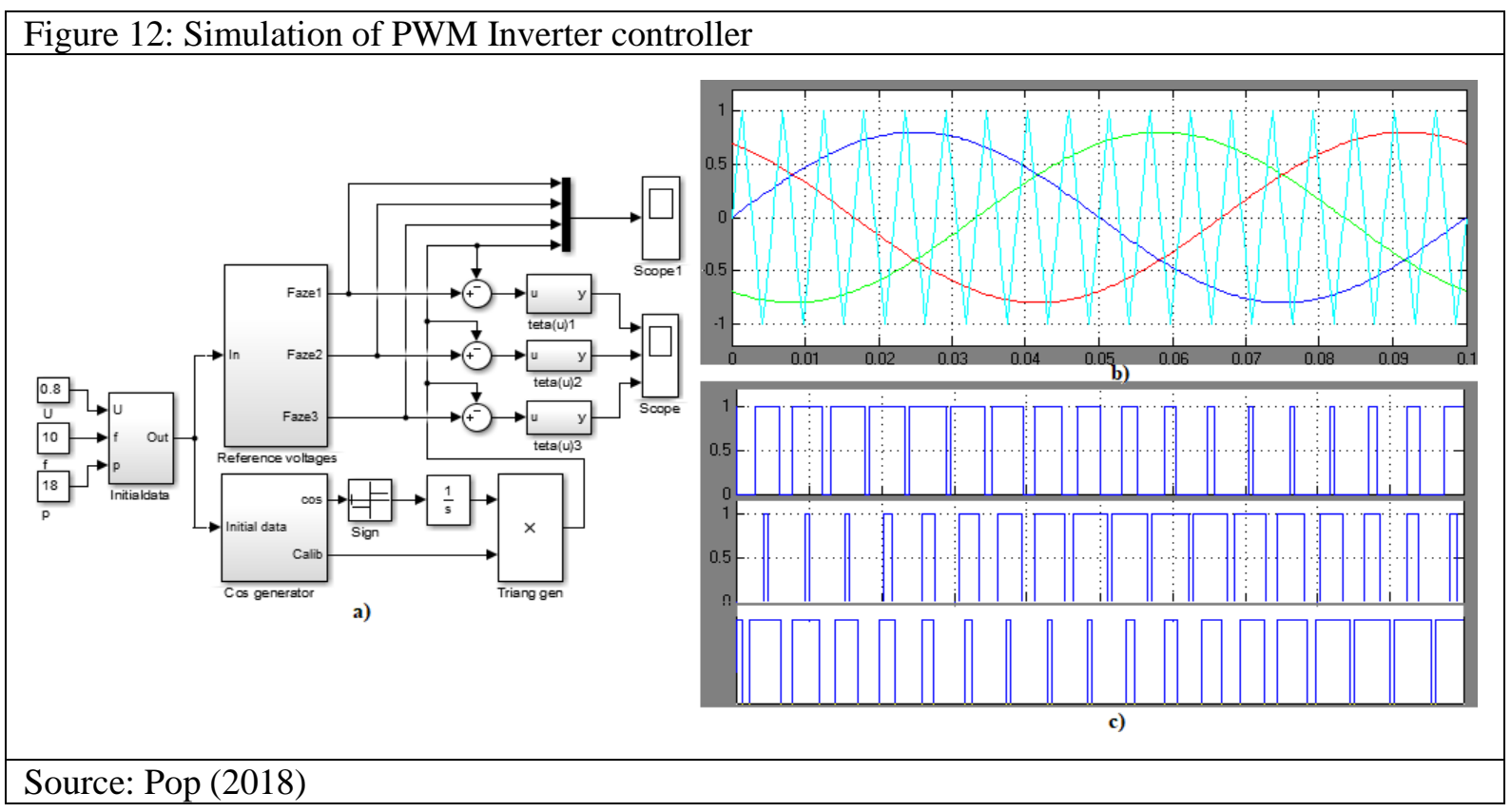

\section{Conclusions}

Distributions theory and its properties are very useful for describing nonlinear phenomena and analyzing sever nonlinear systems control too. 
In this paper are presented some new properties of distributions together with examples of applications. Using the properties of distributions, complex nonlinear problems, like system control design, can be treated much more easily.

In this paper are shown models and simulations results for several discrete control applications used in control engineering and power electronics.

The distributions are suitable for software implementation and by this offer very good support for an embedded software-oriented solution.

The paper can be used as a guide of applied distributions properties to develop a mathematical model and to get simulation results including HIL for process control.

\section{References}

Bertolonffy L. (1972). General System Theory. New York: Library of congress.

Boldea I. \& Nasar S.A. (1992). Vector Control of AC Drive., CRC Press LLC.

Bolton W. (1998). Control engineering, 2. London: Prentice Hall.

Constantinescu S. L. \& Soal K. (1999). Electrische Machinen und Antriebssysteme. Springer.

Davies B. (1998). Integral transformes and their applications. Springer-Verlag.

Dunning G., (2006). Introduction to programmable logic controller. Elsevier.

Gerard F. \& Sursh John M. (1998). Introduction to the Theory of distributions. Cambridge University Press.

Ian Richards L.J. \&Youn Heekyung K. (2013). Theory of distributions. Cambridge University Press.

Ionescu V.\& Varga A. (1994). System Theory (in Romanian). Bucharest: All Publishing House.

Kalman R., Falb P. L. \& Arbib A. (1969). Topics in mathematical system theory. Mc. Graw-Hill.

Kecs W.W. (2003).Distribution theory and applications (in Romanian). Bucharest: The Romanian Academy Publishing House.

Leonhard W. (1996). Control of Electrical Drive. Berlin: Springer Verlag.

Luhmann N. (2013). Introduction to Systems theory. Cambridge: Polity Press.

Mohan N. (2014). Advanced electric drives: Analysis, Control, and Modeling Using MATLAB / Simulink. John Wiley \& Sons.

Pop E.\& Bubatu R. (2012). System Theory 1(in Romanian). Petrosani, Romania: Universitas Publishing House.

Schwartz L. (1951). Théorie des distributions, I, II. Paris: Hermann.

Teodorescu P. P., Kecs W.W. \& Toma A. (2013). Distribution theory: With applications in engineering and physics. WileyVCH Verlag GmbH \& Co. KgaA. DOI: 10.1002/ 9783527653614.

Zemanian A.H. (1998). Distributions Theory and transforme analyses. Mc. Graw-Hill. 